\title{
¿Es la dramatización una estrategia pedagógica, para mejorar la comprensión lectora? (1)
}

Is dramatization a pedagogical strategy for getting a better reading comprehension?

\section{Sonia del Carmen Pérez Balmaceda}

Especialista de la Recreación Ecológica

Fundación Universitaria los Libertadores

Docente de la institución Educativa La Salle

Ocaña - Norte de Santander - Colombia Maestría (T) en Educación

Universidad Autónoma de Bucaramanga sperez844@ unab.edu.co sopeba24@hotmail.com

Integrante del grupo de investigación:

Educación y Lenguaje

\section{Gilberto González}

Magister en M. A. Estudios Latino Americanos

Universidad UCLA - Estados Unidos.

Docente Universidad Autónoma de Bucaramanga ggonzalez4@ unab.edu.co

Artículo recibido el 15 de octubre del 2016

Aprobado el 31 de octubre del 2016 (2) 


\title{
Resumen
}

Trabajar el teatro desde el aula es una propuesta que genera cambio y desarrolla conocimiento. Busca superar las dificultades en preguntas de nivel literal e inferencial para mejorar los resultados en las pruebas Saber. Se trabajó con 22 estudiantes del grado tercero del Colegio La Salle Ocaña, bajo la metodología investigación acción de corte cualitativo, que permitió la práctica reflexiva docente-estudiante, el trabajo mediante juegos, cuentos, fábulas, leyendas y obra teatral, en los cuales se aplicaron talleres para desarrollar la comprensión lectora. Se observó motivación, diálogo, representación de personajes; se amplió el vocabulario, el manejo de espacio, la expresión verbal, la no verbal y la escritura de narraciones. Una estrategia que se sugiere aplicar desde los primeros años de escolaridad.

Palabra Clave: investigación acción, reflexión, talleres, juegos teatrales, comprensión lectora. .

\begin{abstract}
Playing act at school is a proposal that makes social change and develops knowledge. It pursues to overcome difficulties about literal and inferential questions, improving results on Pruebas Saber. This research was applied to twenty-two third grader of La Salle High school, with an investigation-action methodology, and a qualitative share section, allowing a teacher-to-student practice, working on games, tales, fables, legends and plays, workshopping to develop reading comprehension. We could observe motivation, dialogue, role play, new lexicon, space management, verbal and non-verbal expression and telling writing. It is recommended applying this strategy from the early years of scholarship.
\end{abstract}

Key words: Investigation-action, thought, workshop, play, reading comprehension.

\section{Introducción:}

¿Por qué trabajar la dramatización como estrategia pedagógica para desarrollar la compresión lectora? Desarrollar la comprensión lectora en los educandos es un reto de todo docente, pero ¿cómo llegar a ella de manera motivante?, es la pregunta que a diario se realiza y lo que permitió desarrollar la presente investigación.

Las observaciones realizadas en la fase diagnóstica de intervención, reflejan dificultades para responder preguntas de nivel literal e inferencial, situación que demuestra la falta de comprensión del texto que leen, lo que lleva a la docente a cuestionarse acerca de los procesos de comprensión lectora y la posibilidad de proponer estrategias para desarrollar aprendizajes significativos. Se evidenció además que el tiempo que dedican los niños y niñas a leer es solo mientras están en la escuela. 
Mediante una primera intervención a los niños y niñas en un proceso de lectura donde se parte de un juego teatral que los introduce al texto y luego de motivarlos a representarlo se pudo comprobar la posibilidad de concentración, la espontaneidad para participar, la facilidad para contar, resumir el texto y responder preguntas de nivel literal e inferencial.

Por lo anterior este artículo de investigación propone una estrategia pedagógica basada en los juegos teatrales para mejorar la comprensión lectora, siendo el teatro un arte que abarca muchos aspectos en la educación, en España por ejemplo se promueve como la pedagogía teatral, desarrollando la expresión corporal, buena pronunciación, memoria y concentración. Es una estrategia que facilita al educando a representar sus textos de manera dinámica y divertida, busca la integración del grupo, el trabajo en equipo y genera la necesidad de expresarse a un público.

Con este trabajo en el aula se rompe la monotonía, el niño participa, respeta el espacio y la palabra de otro, reconociendo la importancia del diálogo y por ende la necesidad del hombre para convivir con otros.

Azorín (1954), citada por Lilian Parada (2013), califica el teatro escolar como juego escénico, un elemento de la ficción teatral que ayuda a formar el alma y perfeccionar la expresividad para beneficiar la educación estética. El juego dramático es un elemento seguro para que el niño conserve el gusto por crear, a la vez que estimula el desarrollo corporal y aptitudes como la imaginación, la reflexión, la sensibilidad y el sentido social. El autor sugiere que los profesores deben jugar el juego y establecer reglas, incorporando ejercicios corporales e imaginativos. (2013: 40).

Con lo anterior también se comprueba la necesidad de implementar esta estrategia en poblaciones vulnerables donde a través del juego y el teatro se canalizan todos los sentimientos de agresividad, los temores y frustraciones de los niños y niñas de una manera productiva y por ello se ve la necesidad apremiante de aplicarla para lo cual se planteó el siguiente objetivo: Desarrollar la comprensión lectora en los estudiantes del grado tercero mediante una estrategia basada en escritura y juegos teatrales.

Es fundamental permitirles a los estudiantes su aporte frente a sus lecturas, expresando con sus palabras lo que comprenden para llevarlos al desarrollo del pensamiento, por tanto la dramatización es una estrategia que le permite al niño interactuar con el texto, representarlo mediante su propia comprensión.

Con esta estrategia se ha motivado al educando que lea detenidamente los textos que se aplican en el proceso pedagógico, con actividades que le ayudan a mejorar su comprensión, se descubren actitudes en los niños como es: la facilidad de pararse frente a un grupo, la participación en las clases, teniendo presente que es un trabajo realizado con estudiantes de tercero de primaria, y es fundamental crear esta disciplina desde los primeros años de la etapa escolar, reconociendo que la comprensión lectora no se desarrolla solamente desde el pupitre, que un estudiante desarrolla su pensamiento cuando descubre que todo su cuerpo desarrolla significado y los niños lo 
pueden reconocer desde esta estrategia teatral.

\section{Metodología}

El presente proyecto se desarrolló con la investigación - acción la cual es de corte cualitativo. Según Rodríguez (2011: 4) el término "investigación acción" proviene del autor Kurt Lewis y fue utilizado por primera vez en 1944. Esta investigación permite analizar de una marera muy detenida la práctica pedagógica, buscando actividades que generen actitud de cambio en nuestro quehacer pedagógico, además busca generar una transformación en el docente, para que replantee su manera de impartir los conocimientos, haciendo de esta labor, momentos significativos para cada uno de ellos.

Para la aplicación del proyecto se prepararon juegos teatrales al inicio de la clase. Posteriormente se les explicó el tema a los estudiantes y luego se reunieron por pequeños grupos donde se organizaron algunas dramatizaciones de acuerdo al tema explicado, teniendo en cuenta sus actitudes y dándoles la oportunidad de crear e inventar personajes acorde a su edad, siendo esto importante para ellos porque están aportando a sus conocimientos para colocar en práctica lo aprendido.

Los talleres y los juegos teatrales permitieron desarrollar la comprensión lectora en los estudiantes, pues se motivaron a comprender los textos de forma creativa realizando las dramatizaciones.

Se fomentó el trabajo en equipo, la mesa redonda, trabajos grupales, exposiciones, lecturas, dibujos realizados por los mismos educandos.

Todas las actividades realizadas conducen a fortalecer la metodología de la institución, siendo que se trabaja con Escuela Activa la cual fomenta el trabajo en equipo donde el educando es el centro del aprendizaje y el docente es un guía. Según Lowenfeld (1973) Citado por Jacinto (s.f: 15), permite el "desarrollo de la capacidad creadora", fomenta la creatividad y la libre expresión, del mismo modo impulsa satisfacción y seguridad en el educando.

Se aplican una serie de instrumentos como es el diario de campo, donde se hace el registro de las actividades desarrolladas en el aula de clase, teniendo la oportunidad de observar la práctica pedagógica y así mirar cómo resolver los problemas del aula. Resaltando la participación de los niños y subrayando las fortalezas y las debilidades presentadas en el desarrollo de la misma.

En la investigación se desarrollaron talleres los cuales comprendieron una serie de preguntas de nivel literal e inferencial de acuerdo a los cuentos relacionados con el género narrativo y las obras del género dramático; en donde se estudió el diálogo como recurso principal de esta investigación en el área de Lengua castellana.

\section{Resultados}


Los talleres permitieron dar un orden a la organización del trabajo. El primer taller, La Tortuga Gigante de Horacio Quiroga, se organizó con un juego teatral llamado: Soy una serpiente, la participación del grupo fue total, los niños y niñas se observaron felices, se aprendieron el juego y les agrado dirigirlo.

Las actividades de predicción jugaron un papel importante, porque las preguntas de entrada sobre el juego y el uso de imágenes previas a la lectura despiertan la motivación, la intriga y el deseo por continuar el desarrollo de cada taller.

Los niños fueron capaces de representar lo leído con dibujos, identificar personajes, realizar resúmenes, identificaron las diversas partes de su estructura y realizaron dramatizaciones del cuento en el aula de clase. Este último aspecto permitió lograr la integración del grupo, la participación y la disminución de brotes de indisciplina en el aula.

Uno de los elementos para observar y que tomó relevancia para evaluar y hallar resultados en el diario de campo fueron los recursos que jugaron un papel importante en el desarrollo de cada uno de los diferentes talleres, pues son medios que nos llevaron a realizar cada una de las actividades, es de reconocer que cada uno de estos elementos permitieron que las enseñanzas los niños las recibieran de una manera diferente.

Los recursos utilizados en los talleres fueron: El juego teatral como actividad de ambientación, el diálogo, los cuentos, las fábulas, el guion teatral, videos, computador, proyector, teatro en casa, talleres, caparazón de la tortuga, pinturas, cartulina, marcadores, colores, el metro, la regla, reloj, imágenes de animales, hojas de papel bond, crayolas, lectura, disfraz de la tortuga y elementos de juguetes del doctor, marcadores, lápiz, cuadernos, lecturas, crayolas, humanos, cartulina, cauchos, hojas, lápiz, lapiceros cuadernos, una pelota, tijera, taller pedagógico de lectura, textos, dibujos del sol y flores. Preparador de clase, libros, agua, lecturas de leyendas de la región y mitos, imágenes de las partes del pájaro $\mathrm{Cu}$, el elefante y el jabalí, videos, música de expresión corporal, un pito, fotocopias de la obra de teatro La Cobija, imágenes referentes a los personajes que participan en el diálogo, elementos necesarios para la organización del escenario de la obra de teatro, y el mismo salón de clase el cual nos sirvió como escenario, marcadores borrables y el tablero acrílico.

Garzón, (2011: 21) afirma que: Un recurso didáctico es cualesquier material que se posee o se ha elaborado con el propósito de proporcionar ayuda al docente y pueda cumplir su función y al mismo tiempo la del estudiante. Tener presente que los recursos didácticos convienen utilizarse en un argumento pedagógico. Los Recursos Didácticos son todos aquellos implementos utilizados por el docente para apuntalar, perfeccionar, conducir o apreciar el proceso pedagógico que dirige o dispone.

\section{Aprendizaje}

La efectividad en las diferentes actividades: 
- Orientación en cada uno de los procesos de las lecturas: a los niños los motiva a leer, estar atentos, interactuar con el texto y comunicar sus ideas.

- En el desarrollo de las carteleras la docente está pendiente del trabajo que se está realizando y los orienta y anima para que todos participen.

- Los niños con lo visto en la clase pueden realizar sus propios escritos, pueden hacer resúmenes, dibujar e ilustrar el tema visto, además sacar sus conclusiones y hasta relacionar lo leído con su vida personal.

- Después de analizar el taller y la lectura de los diferentes cuentos, la docente los motiva para que respondan preguntas de nivel literal e inferencial.

- La docente afirma que los niños alcanzaron niveles de comprensión cuando revisa los cuentos escritos por los mismos niños, encontrando que están enriqueciendo su vocabulario con palabras nuevas y esto les permite realizar escritos con sentido y a la vez tienen la capacidad de expresarlos a través de dibujos.

- En la representación de los diferentes personajes que el niño quiere imitar y es ahí donde se involucra en el ser que quiere representar, lo toma como un juego, el cual lo lleva a desarrollar su propio pensamiento dejando la cotidianidad de la clase e imaginando como expresar sus sentimientos y capacidades de llegar a los demás en un lenguaje no conocido para el niño, el hecho de compartir con alegría, acatar órdenes y reglas en el juego.

- Cada uno de los talleres desarrollados permitió el análisis de la aplicación de los diversos valores. Además la puesta en escena de las obras permitió un trabajo colaborativo de manera eficaz.

Para esto Garzón, (2011: 28) afirma que los contenidos, experiencias, habilidades, capacidades que los estudiantes logran obtener como resultado de las habilidades pedagógicas que el establecimiento les entrega, la enseñanza nace como un proceso de interiorización de la idea adquirida por medio de la experiencia que cada estudiante ha coexistido en la ejecución de los trabajos planteados por el docente.

\section{El juego como recurso educativo}

Una de las acciones relevantes dentro del juego es la integración de la docente realizando las actividades con los niños, eso es motivante para ellos, se les observa expresiones de alegría en sus rostros y de confianza durante la actividad, a los niños les gustó el ritmo, la música y la letra tanto de las canciones como de las dinámicas que se realizaron.

En los juegos teatrales se utilizan diversos espacios institucionales como el patio de recreo, se observa cómo se acomodan y realizan diferentes movimientos que le generan acciones donde improvisan lo que quieren llegar a representar, a creer en sus propias capacidades y descubrir oportunidades que puede alcanzar a desarrollar, potencialidades en su expresión corporal y lenguaje. Desarrollando la autoestima, y la libertad de expresar sus sentimientos y emociones. 
En el desarrollo de los juegos teatrales las niñas son las más interesadas en la participación y motivan a sus compañeros a que los realicen, de esta manera ayudan a que pierdan el miedo y a integrarse de manera espontánea.

Así García (2013) menciona a Nevado, (2008) quien refiere que a lo largo de la historia el juego ha sido considerado como un recurso educativo explotado por el hombre desde la antigüedad, y aunque en un principio, no fue tenido en cuenta como parte del proceso educativo, gracias a las diferentes aportaciones de la pedagogía, la psicología, la filosofía, la antropología o la sociología, la educación ha dado un giro aprovechando todas las ventajas que su uso conlleva. Diferentes estudios han demostrado que el juego incluye pensamiento creativo, solución de problemas, habilidades para aliviar tensiones y ansiedades, capacidad para adquirir nuevos entendimientos, habilidad para usar herramientas y desarrollo del lenguaje.

\section{Conclusiones}

Es importante trabajar los juegos teatrales con los niños porque genera en ellos capacidades en el conocimiento, despierta habilidades para integrarse y desarrolla actitudes de participación activa en el aula.

Uno de los factores que envuelve al docente de manera negativa es el del tiempo porque al despertar la motivación, los juegos teatrales hacen que los niños propongan diversas actividades en una sola temática. Es allí donde el docente sintiendo el temor de no avanzar debe permitir la reflexión de analizar lo que realmente se está logrando para concluir que en ocasiones los mismos estudiantes marcan el ritmo.

Las respuestas en cada uno de los talleres y el material de producción textual son muestra para el docente que los niños alcanzaron niveles de comprensión lectora. Al igual que mejoras de su vocabulario, la motivación y el desarrollo artístico a través de sus dibujos.

El juego permite descubrir, explorar y conocer. De esta manera se logró hacer que los niños identificaran la estructura del cuento y escribieran sus propios cuentos. Se integraran al trabajo en grupo y disfrutaran de la lectura de manera divertida.

El papel del docente mediador debe permitir el uso y apropiación de estrategias que favorezcan la solución de las necesidades del grupo. Los juegos teatrales permitieron la innovación y la transformación para los educandos, el objetivo al iniciar la Maestría fue aprender a cambiar la manera de impartir los saberes y el diario de campo permitió la reflexión constante para lograrlo.

\section{Referencias}

García, N., Rodríguez, S., Herráis , D., Prieto de la Higuera, M., Martinez Solla, M., Picazo Zabala, I., Escámez, B. 
(2010-2011).google. Obtenido de google: https://www.uam.es/personal_pdi/stmaria/jmurillo /InvestigacionEE/Presentaciones/Curso_10/Inv_accion_trabajo.pdf. Heladio, M. (1985). Teatro Infantil Para

La Enseñanza En Primaria. Bogota: Codema. Jacinto, J. E. (s.f). El juego

como estrategia didáctica en la Expresión Plástica. Educación Infantil. Obtenido de google.com: https://uvadoc.uva.es/bitstream/10324/1123/1/TFG-B.53.pdf Marcela, M. T. (2011). ¿La escuela o la cuna? Evidencias,sobre su aportación al rendimiento de los estudiantes de américa latina". Profesorado., 1-24. Motos Tomás,

N. A. (2012). El Taller de Teatro. Bogotá: Acteadro. Parada, L. (2013). google.com. Recuperado el 6 de septiembre de 2016, de Universidad Autonoma de Madrid.:

https://repositorio.uam.es/bitstream/handle/10486/13473

/63375_parada\%20alfonso\%20lilian.pdf?sequence=1 Salle,

I. E. (20011). Proyecto Educativo institucional. Ocaña. Sonia, P. (2016). Los Juegos Teatrales Como

Estrategia

Pedagogica Para Mejorar La Comprensión Lectora. 0caña. Torrecilla, M. F. (2011). Revista Ibero

Americana Sobre

Calidad, Eficiencia y Cambio en la Educación. Reice, 1- 22.

\section{Notas}

(1). Citar este artículo como: Pérez, S. \& González G. (2016). “Es la dramatización una estrategia pedagógica, para mejorar la comprensión lectora?”. En: Revista La Tercera Orilla (17). Bucaramanga: Universidad Autónoma de Bucaramanga.

(2). Artículo arbitrado por: Nicolás Cadavid. Magíster en Artes Visuales, Universidad de Chile. Docente Universidad Autónoma de Bucaramanga. 